\title{
CHANGING PATTERN OF MORTALITY IN ENGLAND AND WALES II. MATERNAL MORTALITY
}

\author{
BY \\ WALLIS TAYLOR* AND MARJORIE DAUNCEY \\ Department of Medical Statistics, University of Birmingham
}

The crude death rate for females fell from $13 \cdot 7$ in 1911 to 11.6 in 1931 . The Life Table death rate, i.e. the death rate duly standardized with reference to the changing age structure of the population fell from $18 \cdot 1$ to $15 \cdot 9$ in the same period. Meanwhile the infant mortality rate had also fallen from 109 in 1911-15 to 62 in the quinquennium 1931-5; but no such decline took place in deaths associated with childbirth. In 1921, the maternal mortality rate for England and Wales was 4.09 per thousand live births; in 1931 it was $4 \cdot 28$, but by 1941 it had fallen to $2 \cdot 9$, and by 1951 to $0 \cdot 84$. We may fairly confidently predict that by 1961 the current rate will not exceed half the latter figure. The circumstances of these very large changes are worthy of attention in retrospect, for it is clear that medical opinion at the time when the decline set in was neither capable of forecasting it nor indeed of explaining why the maternal mortality rate had till then failed to follow the same course as other death rates in that period.

The year 1934 registers a higher figure for puerperal mortality than for any since 1911 , and the failure of the puerperal mortality rate to decline with the general death rate prompted the Ministry of Health to undertake an investigation, the findings of which became public in 1937. In summarizing them, the Report states frankly, but not informatively, that:

... it appears to be the collective influence of many factors which predisposes towards puerperal mortality and the effects of the individual factors cannot be dissociated and separately assessed.

Before examining the decline, it is first necessary to define the meaning of the term maternal mortality, more especially because our period covers some years in which the public statistics are referable to the 4th revision and others in which they are referable to the 5th revision of the list of causes of death used in the reports of the Registrar-General of England and Wales.

The following definition is taken from the special Ministry of Health Report (1937):

With almost negligible exceptions, those deaths in which pregnancy or childbirth was a primary cause of death are classified by the Registrar-General into one

*Holder of a Research Fellowship from the Rockefeller Foundation group, namely, puerperal mortality. There remains, however, a group of cases which are excluded from the deaths "Classed to" pregnancy or childbirth by the operation of the "code", but in which some mention is made on the certificate of pregnancy or childbirth ... these deaths are collected by the Registrar-General and described as deaths "associated with" pregnancy and childbirth.

Since the primary cause of death in this group of associated deaths is non-maternal, the rates discussed have been calculated on the puerperal mortality

TABLE I

PUERPERAL MORTALITY, 1921-52, IN TERMS OF THE 4TH AND 5TH REVISIONS

\begin{tabular}{|c|c|c|c|c|c|}
\hline \multirow{3}{*}{ Year } & \multirow{3}{*}{ Live Births } & \multirow{2}{*}{\multicolumn{2}{|c|}{$\frac{\text { 4th Revision }}{\text { Puerperal Mortality }}$}} & \multirow{2}{*}{\multicolumn{2}{|c|}{$\frac{\text { Sth Revision }}{\text { Puerperal Mortality }}$}} \\
\hline & & & & & \\
\hline & & No. & $\begin{array}{l}\text { Per } 1000 \\
\text { Live Births }\end{array}$ & No. & $\begin{array}{l}\text { Per } 1000 \\
\text { Live Births }\end{array}$ \\
\hline $\begin{array}{l}1921 \\
1922 \\
1923 \\
1924 \\
1925 \\
1926 \\
1927 \\
1928 \\
1929 \\
1930 \\
1931 \\
1932 \\
1933 \\
1934 \\
1935 \\
1936 \\
1937 \\
1938 \\
1939 \\
1940 \\
1941 \\
1942 \\
1943 \\
1944 \\
1945 \\
1946 \\
1947 \\
1948 \\
1949 \\
1950 \\
1951 \\
1952\end{array}$ & $\begin{array}{l}848,814 \\
780,124 \\
758,131 \\
729,933 \\
710,582 \\
694,563 \\
654,172 \\
660,267 \\
643,673 \\
648,811 \\
632,081 \\
613,972 \\
580,413 \\
597,642 \\
598,756 \\
605,292 \\
610,557 \\
621,204 \\
614,479 \\
590,120 \\
579,091 \\
651,503 \\
684,334 \\
751,478 \\
679,937 \\
820,719 \\
881,026 \\
775,306 \\
730,518 \\
697,097 \\
677,529 \\
673,735\end{array}$ & $\begin{array}{l}3325 \\
2973 \\
2895 \\
2847 \\
2900 \\
2863 \\
2691 \\
2921 \\
2791 \\
2855 \\
2601 \\
2587 \\
2618 \\
2748 \\
2457 \\
2301 \\
1988 \\
1917 \\
1815 \\
1570 \\
1606 \\
1600 \\
1550 \\
1428 \\
1206 \\
1157 \\
1014 \\
776 \\
696 \\
593 \\
542 \\
477\end{array}$ & $\begin{array}{l}3 \cdot 92 \\
3 \cdot 81 \\
3 \cdot 82 \\
3 \cdot 90 \\
4 \cdot 08 \\
4 \cdot 12 \\
4 \cdot 11 \\
4 \cdot 42 \\
4 \cdot 34 \\
4 \cdot 40 \\
4 \cdot 11 \\
4 \cdot 21 \\
4 \cdot 51 \\
4 \cdot 60 \\
4 \cdot 10 \\
3 \cdot 80 \\
3 \cdot 26 \\
3 \cdot 09 \\
2 \cdot 95 \\
2 \cdot 66 \\
2 \cdot 77 \\
2 \cdot 46 \\
2 \cdot 26 \\
1.90 \\
1 \cdot 77 \\
1 \cdot 41 \\
1 \cdot 15 \\
1 \cdot 00 \\
0.95 \\
0 \cdot 85 \\
0 \cdot 80 \\
0 \cdot 71\end{array}$ & $\begin{array}{l}3475 \\
3107 \\
3025 \\
2975 \\
3030 \\
2992 \\
2812 \\
3052 \\
2917 \\
2983 \\
2706 \\
2683 \\
2737 \\
2880 \\
2590 \\
2431 \\
2142 \\
2096 \\
1997 \\
1641 \\
1678 \\
1672 \\
1620 \\
1492 \\
1260 \\
1209 \\
1060 \\
811 \\
727 \\
620 \\
566 \\
498\end{array}$ & $\begin{array}{l}4 \cdot 09 \\
3 \cdot 98 \\
3 \cdot 99 \\
4 \cdot 08 \\
4 \cdot 26 \\
4 \cdot 31 \\
4 \cdot 30 \\
4 \cdot 62 \\
4 \cdot 53 \\
4 \cdot 60 \\
4 \cdot 28 \\
4 \cdot 37 \\
4 \cdot 72 \\
4 \cdot 82 \\
4 \cdot 33 \\
4 \cdot 02 \\
3 \cdot 51 \\
3 \cdot 37 \\
3 \cdot 25 \\
2 \cdot 78 \\
2 \cdot 90 \\
2 \cdot 57 \\
2 \cdot 37 \\
1 \cdot 98 \\
1 \cdot 85 \\
1 \cdot 47 \\
1 \cdot 20 \\
1 \cdot 05 \\
0 \cdot 99 \\
0 \cdot 89 \\
0 \cdot 84 \\
0 \cdot 74\end{array}$ \\
\hline
\end{tabular}

4th Revision 1921-39 as given in 4th revision. 1940-52 converted to 4th revision from 6th

5th Revision 1921-30 converted to 5th revision from 4th 1931-39 as given in 5th revision $1940-52$ as given in 6th revision

Conversion ratio from 4 th to 5 th revisions $=1.045$ 
alone. An appendix sets forth some of the changes made in successive revisions of the RegistrarGeneral's Tables.

The trend of the puerperal mortality rate can be seen in Table I. The two sets of figures cited differ but little and follow the same course. How spectacular was the turning-point is clearer when we examine the graphical presentation of the data. For the reasons outlined in a previous paper in this series (Taylor, 1954) Fig. 1 exhibits them on a logarithmic scale and this clarifies the point at which a sustained decline begins. Here we may easily be misled by cursory inspection into thinking that 1935 marks the first year of decline from the high plateau of the period before 1934. It is true that the figure for 1935 is lower than that for 1934 , and that the figure for 1936 is lower than that for 1935, but the 1936 rate is itself higher (5th revision) or not appreciably lower (4th revision) than the 1922 rate. We cannot therefore pinpoint 1936 as marking the start of a systematic fall in contradistinction to a temporary recession from an abnormally high value. As in a previous study of infant mortality (Taylor, 1954), we shall regard annual values as suspect and define a sustained decline as:

A decline which has continued from a certain date D to the present time on the understanding that:

(a) there is recorded on date $\mathrm{D}$ a level as low as in any previous year; (b) we neglect annual fluctuations if the mean figure for a given quinquennium from $D$ onwards is no greater than its predecessor.

In this context, we accordingly regard 1937 as the first year of sustained decline. Ever since then the decline has continued, and the log-graph plot shows how regular it has been, the more so because a fixed proportionate decline on this scale follows the course of a straight line and an increasing proportionate decline follows the course of a curve which is downwards. The fall was not associated with the decline of live births from 1921 onwards. In that year they totalled 848,814. In 1952 they were 673,735, and in 1934 fertility in England and Wales was at a minimum. There were in 1934 only 597,642 live births, 70 per cent. of the figure for 1921; but the maternal mortality rate of 1934 considerably exceeded that of 1921 .

In seeking elsewhere an explanation of the decline, it is advisable to break down the general puerperal mortality by cause of death. Accordingly, Table II exhibits the principal causes of maternal death during most of this period. As the Appendix explains, strict comparability is not possible after 1950 because of the drastic changes in the 6th revision of the standard mortality classifications.

The eight main categories in Table II (overleaf) cover 93.5 per cent. of puerperal deaths in 1931 and account for 91 per cent. of deaths in 1949. From

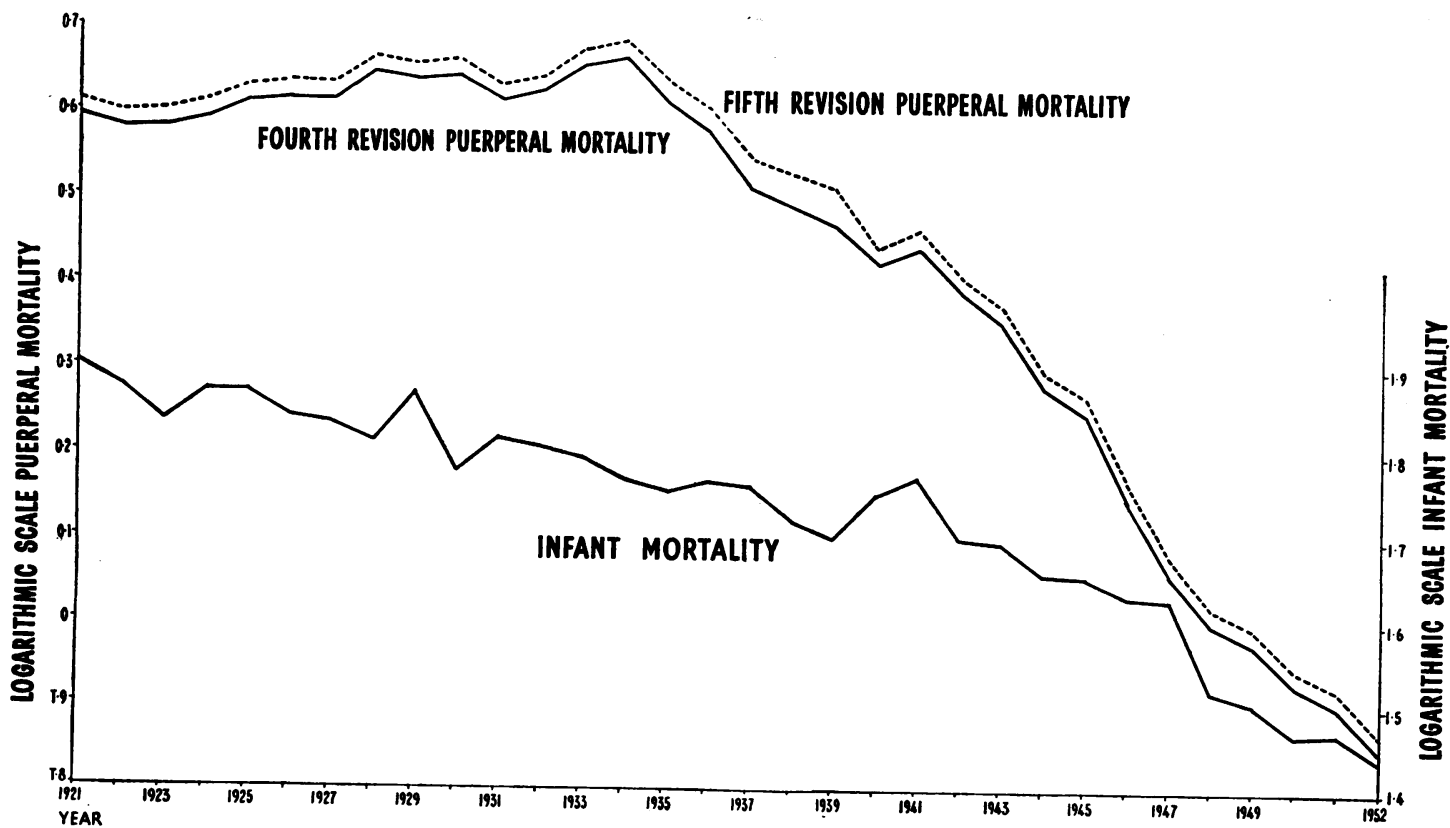

Fig. 1. - Course of puerperal mortality and infant mortality, 1921-52 (rates per 1,000 live births on logarithmic scale). 
these we see that "toxaemias of pregnancy and puerperal toxaemias" and "infection during childbirth and the puerperium" alone represented 52.5 per cent. of total puerperal deaths in 1931. These, with the third largest group, "haemorrhage of pregnancy and childbirth", are shown in Fig. 2, which discloses the change of their relative importance during the period 1931-49. The most dramatic decline is that of "infection during childbirth and the puerperium", which fell from 1.41 in 1931 to 0.11 in 1949. In 1931, "infection" accounted for $34 \cdot 3$ per cent. of total puerperal deaths, making it by far the largest single cause of death, but by 1949 this accounted for only $11 \cdot 6$ per cent. of puerperal deaths. Meanwhile, the percentage of deaths from "toxaemias" had risen from 18.2 per cent. in 1931 to $28 \cdot 7$ per cent. in 1949 , thus replacing "infections" as the largest single cause of puerperal death.

TABLE II

PRINCIPAL CAUSES OF PUERPERAL MORTALITY AS CLASSIFIED IN 5TH REVISION

(Percentage of total deaths)

\begin{tabular}{|c|c|c|c|c|c|c|}
\hline \multicolumn{2}{|r|}{ Classification } & \multicolumn{5}{|c|}{ Year } \\
\hline No. & Cause of Death & 1931 & 1935 & 1940 & 1945 & 1949 \\
\hline $\begin{array}{l}140 \\
141 \\
143\end{array}$ & \multirow{6}{*}{ 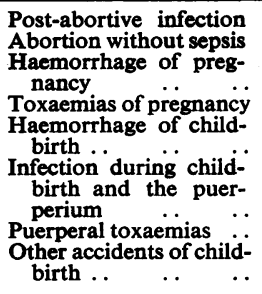 } & $\begin{array}{r}10 \cdot 4 \\
6 \cdot 2\end{array}$ & $\begin{array}{r}12 \cdot 6 \\
5 \cdot 3\end{array}$ & $\begin{array}{l}9.6 \\
6.6\end{array}$ & $\begin{array}{r}13 \cdot 8 \\
4 \cdot 7\end{array}$ & $\begin{array}{r}10 \cdot 7 \\
4 \cdot 9\end{array}$ \\
\hline $\begin{array}{l}144 \\
146\end{array}$ & & $\begin{array}{l}2 \cdot 4 \\
4 \cdot 7\end{array}$ & $\begin{array}{l}2 \cdot 1 \\
4 \cdot 9\end{array}$ & $\begin{array}{l}1 \cdot 9 \\
8 \cdot 2\end{array}$ & $\begin{array}{l}1 \cdot 4 \\
6 \cdot 7\end{array}$ & $\begin{array}{l}2 \cdot 2 \\
7 \cdot 8\end{array}$ \\
\hline 147 & & $9 \cdot 8$ & $9 \cdot 2$ & $12 \cdot 3$ & $14 \cdot 0$ & $12 \cdot 1$ \\
\hline \multirow{3}{*}{$\begin{array}{l}148 \\
149\end{array}$} & & $34 \cdot 3$ & $32 \cdot 4$ & $20 \cdot 7$ & $13 \cdot 3$ & $11 \cdot 6$ \\
\hline & & $13 \cdot 5$ & $13 \cdot 9$ & $16 \cdot 1$ & $18 \cdot 9$ & $20 \cdot 9$ \\
\hline & & $12 \cdot 2$ & $13 \cdot 2$ & $17 \cdot 8$ & $20 \cdot 1$ & $20 \cdot 9$ \\
\hline & Total & $93 \cdot 5$ & $93 \cdot 6$ & $93 \cdot 2$ & $92 \cdot 9$ & $91 \cdot 1$ \\
\hline
\end{tabular}

As elsewhere emphasized (Taylor, 1954), the interpretation of a time sequence of this sort is beset with many pitfalls, more especially because many putative contributory agencies come into operation gradually and to a greater or less extent synchronously. One may put a date to an Act of Parliament or to a therapeutic discovery, but the full implementation of a social service such as the maternity and child welfare clinics is necessarily a slow process; and the competent adoption of a new curative measure in general practice may also spread over several years. Only when we can pinpoint the start of a sudden sustained decline of a death rate, and relate it to the introduction of a new curative measure of indisputable efficacy which has come swiftly into widespread use, can we safely ascribe significance to the latter. Now it happens that the maternity welfare services had been extending their terrain appreciably during a quinquennium antedating the

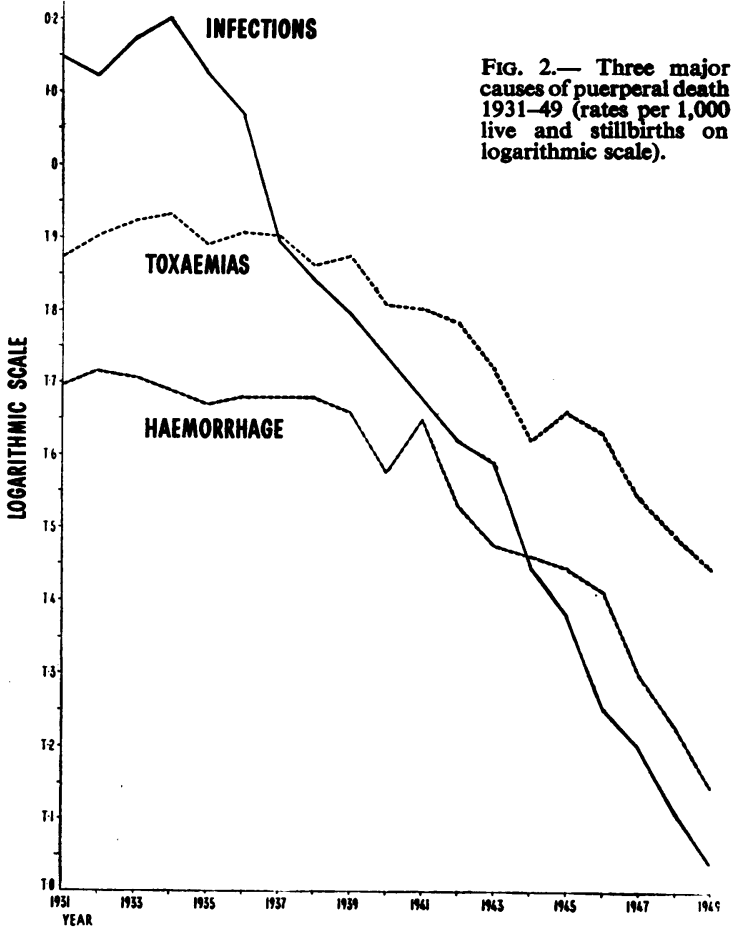

start of the decline under discussion. It also happens that a bill to set up an organized midwifery service was introduced in 1936; but we may be certain that any beneficial consequences were gradual and not immediate. On the other hand, we can put a fairly precise date to the introduction into general use of a new treatment for puerperal sepsis, and we have already seen that the reduction of puerperal sepsis was the outstanding feature of the decline.

From 1930 Leonard Colebrook had studied puerperal fever in Queen Charlotte's Hospital Isolation Block, concentrating on cases involving haemolytic streptococci. At this time one-third of maternal deaths were due to sepsis, and the haemolytic streptococci were responsible for about 75 per cent. of fatal cases. It was not, however, until 1935 that Lancefield and Hare showed that, by using serological methods, these organisms could be divided into at least nine major groups (A to $\mathrm{K}$ ), and that nearly all severe infection by haemolytic streptococci was caused by those of Group A. In the same year "Prontosil" was discovered in Germany. In a properly controlled experiment with this drug, Colebrook achieved a 75 per cent. reduction of mortality due to haemolytic streptococcal infection; and we may confidently assert that the use of sulphonamides quickly became widespread from 1937 onwards. Here, therefore, we seemingly 
encounter one of the rare situations which endorse the identification of an agency of major importance as contributory to a statistical trend. Nor is it unlikely that the introduction of antibiotics has some relevance to the steepening gradients after 1943, but in the 1940s we have to take stock of new conditions. Throughout the later period, other agencies may also well have played a by no means unimportant role, e.g. the introduction of aseptic techniques, the reduction of anaemia among mothers, the control of haemorrhage, and the development of the blood transfusion service.

The Future.-The most satisfactory fit to the curve of puerperal mortality is that given by a quadratic parabola fitted for the years 1934-52.
This method gives us an expected puerperal mortality rate of 0.03 per 1,000 live births in 1962. A logarithmic curve gives a less satisfactory fit, but extrapolation therefrom would lead us to forecast a fall indefinitely beyond 1952, with a rate of approximately $0 \cdot 26$ for 1962 . In any event, it seems most unlikely that the maternal mortality rate at the end of the coming decade will be as high as half the current figure.

Acknowledgement is due to Prof. Lancelot Hogben, F.R.S., for advice and assistance.

\section{REFERENCES}

Ministry of Health (1937). "Report on an Investigation into Maternal Mortality." Cmd. 5422. H.M.S.O., London.

Taylor, W. (1954). British Journal of Preventive and Social Medicine, 8, 1 .

\section{APPENDIX}

In tracing the trend of puerperal mortality over a period of years, the changes in classification in the causes of death given in the decennial revisions of the international list must be borne in mind. Accordingly, in Fig. 1, the puerperal mortality rate from 1921 has been expressed in terms of the 4th revision (1929) and of the 5th revision (1938) by means of a conversion ratio, 1.045 (see Table I). The main difference in the total figures of puerperal mortality given in these two revisions is the inclusion in the 5th revision of deaths due to criminal abortions, i.e. those which were the subject of a coroner's inquest, which had previously been classified by the Registrar-General as "deaths from violence" and had consequently not been included in the puerperal group in the 4th and earlier revisions.

When tracing the course of any one cause through the revisions, certain variations in terminology and grouping occur.

Some of the more important causes of death are shown in the Appendix Table. The four major groups are roughly comparable, but the sections within these groups, even with the same title, are not comparable.

APPENDIX TABLE

\begin{tabular}{|c|c|c|c|c|c|c|}
\hline \multirow[t]{3}{*}{ Revision } & \multicolumn{2}{|r|}{ 4th } & \multicolumn{2}{|r|}{5 th } & \multicolumn{2}{|r|}{6 th } \\
\hline & No. & Cause of Death & No. & Cause of Death & No. & Cause of Death \\
\hline & $\begin{array}{l}145 \\
148 \\
146 \cdot 2\end{array}$ & $\begin{array}{l}\text { Puerperal sepsis } \\
\text { Puerperal phlegmasia, alba } \\
\text { dolens, embolism, and sudden } \\
\text { death } \\
\text { Puerperal pyelitis and pyelo- } \\
\text { nephritis (after delivery) }\end{array}$ & 147 & $\begin{array}{l}\text { Infection during childbirth } \\
\text { and the puerperium }\end{array}$ & $\begin{array}{l}680 \\
681 \\
682 \\
683 \\
684\end{array}$ & $\begin{array}{l}\text { Puerperal urinary infection with- } \\
\text { out other sepsis } \\
\text { Sepsis of childbirth and the } \\
\text { puerperium } \\
\text { Puerperal phlebitis and thrombosis } \\
\text { Pyrexia in the puerperium } \\
\text { Puerperal pulmonary embolism }\end{array}$ \\
\hline \multirow[t]{3}{*}{$\begin{array}{l}\text { Classi- } \\
\text { fication }\end{array}$} & $\begin{array}{c}144 \\
\text { Part of } 141 \cdot 1\end{array}$ & $\begin{array}{l}\text { Puerperal haemorrhage, plus } \\
\text { Accidental haemorrhage of } \\
\text { pregnancy, and antepartum } \\
\text { haemorrhage without abortion }\end{array}$ & $\begin{array}{l}146 \\
143\end{array}$ & $\begin{array}{l}\text { Haemorrhage of childbirth } \\
\text { and the puerperium, plus } \\
\text { Haemorrhage of pregnancy }\end{array}$ & $\left\{\begin{array}{c}670 \\
\text { part of } \\
671,672 \\
643 \\
644\end{array}\right.$ & $\begin{array}{l}\text { Delivery with placenta praevia, } \\
\text { plus } \\
\text { Delivery with retained placenta } \\
\text { and other postpartum } \\
\text { haemorrhage } \\
\text { Placenta praevia } \\
\text { Other haemorrhage of pregnancy }\end{array}$ \\
\hline & $\begin{array}{l}\text { Part of } 146 \\
\text { Part of } 147 \\
\text { Part of } 125.1\end{array}$ & $\begin{array}{l}\text { Puerperal albuminuria and } \\
\text { convulsions } \\
\text { Other toxaemias of pregnancy } \\
\text { Acute yellow atrophy }\end{array}$ & 144 & Toxaemias of pregnancy & $\begin{array}{l}642 \cdot 0,642 \cdot 1 \\
\left\{\begin{array}{l}\text { Part of } 642.4 \\
\text { Part of } 642.5\end{array}\right.\end{array}$ & $\begin{array}{l}\text { Hypertensive and renal disease of } \\
\text { pregnancy. } \\
\text { Hyperemesis gravidarum (part) } \\
\text { Other toxaemias of pregnancy } \\
\text { (part) }\end{array}$ \\
\hline & $\begin{array}{l}\text { Part of } 146 \\
\text { Part of } 147 \\
\text { Part of } 125 \cdot 1\end{array}$ & $\begin{array}{l}\text { Puerperal albuminuria and } \\
\text { convulsions } \\
\text { Other toxaemias of pregnancy } \\
\text { Acute yellow atrophy }\end{array}$ & 148 & Puerperal toxaemias & $\begin{array}{l}642 \cdot 2 \\
642 \cdot 3 \\
685 \\
686 \\
642 \cdot 4 \\
642 \cdot 5\end{array}$ & $\begin{array}{l}\text { Pre-eclampsia of pregnancy } \\
\text { Eclampsia of pregnancy } \\
\text { Puerperal eclampsia } \\
\text { Other puerperal toxaemia } \\
\text { Hyperemesis gravidarum (part) } \\
\text { Other toxaemias of pregnancy } \\
\text { (part) }\end{array}$ \\
\hline
\end{tabular}

